\title{
AVALIAÇÃO DA APRENDIZAGEM E EXCLUSÃO SOCIAL
}

\section{L'évaluation de la apprentissage et l'exclusion social}

\author{
Neuza Bertoni Pinto ${ }^{1}$ \\ Cláudia Mara Soares da Silva ${ }^{2}$
}

\section{Resumo}

A exclusão, outrora tratada como categoria dos processos sociais, é analisada nesse artigo como categoria do processo pedagógico desenvolvido na escola. A forma de avaliar a aprendizagem dos alunos pode se constituir em um mecanismo excludente mesmo nas propostas mais inovadoras das políticas educacionais voltadas para a democratização do acesso e permanência dos alunos na escola. Com o objetivo de discutir as relações entre avaliação da aprendizagem e exclusão escolar, o presente estudo analisa as características de uma avaliação da aprendizagem comprometida com a qualidade do ensino e com a inclusão cidadã do aluno da educação básica, apontando a dimensão formativa da avaliação como fator fundamental na efetivação da aprendizagem necessária ao sucesso da escolarização dos alunos social e culturalmente marginalizados.

Palavras-chave: Exclusão; Avaliação da aprendizagem; Avaliação formativa.

1 Professora do Curso de Pedagogia e do Programa de Mestrado em Educação da Pontifícia Universidade Católica do Paraná - PUCPR- Rua Prof. Arthur Loyola, 85, ap. 53 - Cabral- CEP: 80035-100 - Curitiba PR . e-mail: neuzard@uol.com.br

2 Mestranda do Programa de Mestrado em Educação da Pontifícia Universidade Católica do Paraná- PUCPR e Professora da Rede de Ensino Municipal de Curitiba/PR - Rua 12, n 17 Moradia 23 de agosto- Posternak - CEP: 81930350 - Curitiba- PR. e-mail: profclaudia@bol.com.br 


\section{Résumé}

L'exclusion, il y a bien longtemps traité comme catégorie aux processus sociaux, il est analysé dans cet article comme catégorie du processus pédagogique développé dans l'école. La forme pour évaluer l'apprentissage deséleves peutconstituer dansum mécanisme d'exclusion dans les propositions les plus innovatrices de la politique éducative a orienté sur la démocratisation de l'accèss et permanence des éleves dans l'école. Avec l'objectif pour discuter les relations d'évaluation d'apprentissage et concernant l'exclusion d'école, la présente étude analyse les caractéristiques d'une évaluation compromis avec la qualité de l'éducation et de l'inclusion citoyen des éleves de l'éducation de base, dirigeant la dimension formatrice de l'évaluation en tant que facteur de base dedans l'éfetivation d'apprentissage nécessaire au succés de la scolarisation des éleves culturel et socialement marginalisés.

Mots-clé: Exclusion; Évalution d’apprentissage; Évaluation formatrice.

O sociólogo francês Dubet (2003), abordando as relações entre educação e exclusão, analisou os efeitos da exclusão social na escola. Lembrando que a exclusão, além de ser uma categoria dos processos sociais, é também uma dimensão da experiência escolar dos alunos, o autor mostra que a escola democrática, mesmo afirmando a igualdade de todos, mantém em seus processos pedagógicos inúmeros mecanismos internos de exclusão. Um deles torna-se mais evidente quando a escola afirma a igualdade de todos, sobretudo, quando se refere à igualdade de talentos e potencialidades, premissa muito visível nas práticas de avaliação da aprendizagem dos alunos. $\mathrm{O}$ presente artigo busca discutir as implicações das formas de avaliação escolar no processo de exclusão dos alunos da educação básica.

\section{A exclusão escolar na educação básica}

Face à complexa sociedade atual em que a maioria dos problemas sociais centram-se nas periferias das grandes cidades, a escola de massas vem transformando seu vocabulário, como observa Dubet (2003). O aluno, referenciado em épocas anteriores como um estudante proveniente de camadas operárias, é agora o "aluno difícil", termo que está ligado aos grandes problemas sociais como desemprego, violência, delinqüência, abandono escolar. Para o autor, as transformações sociais que afetam a escola alteram não só a geografia social, mas também a política educacional; os novos problemas de exclusão, além de mudar as representações que a escola possuía em relação a seus atores, inspiram novas ações educativas visando garantir a escolarização dos alunos. Entretanto, referindo-se à sociedade francesa, Dubet (2003, p. 32) 
lembra que se outrora a escola parecia "justa e neutra", mesmo não ensinando conhecimentos úteis e produtivos, a partir de 1960 ela não está mais protegida da exclusão, hoje ela é percebida como "agente ativo da exclusão social". Se nos anos 30, a escola republicana não excluía os alunos era porque "a grande maioria dos jovens tinha acesso ao emprego, independentemente de suas qualificações escolares" (p. 33).

Com efeito, a exclusão escolar é o resultado 'normal' da extensão de uma escola democrática de massa que afirma ao mesmo tempo a igualdade dos indivíduos e a desigualdade de seus desempenhos. Nesse sentido, a escola integra mais e exclui mais que antes, apesar de seus princípios e suas ideologias, e funciona cada vez mais como o mercado, que é, em sua própria lógica, o princípio básico da integração e da exclusão (DUBET, 2003, p. 44).

As constatações do sociólogo francês não são diferentes para 0 Brasil. As políticas públicas voltadas à democratização da educação básica brasileira que há décadas tentam solucionar a escolarização da população das classes marginalizadas não têm garantido o sucesso escolar do aluno. As ações desencadeadas pelos governos para garantir a democratização das oportunidades educacionais, a inclusão e permanência do aluno na escola, apesar das propostas inovadoras, especialmente as que pretendem atender os alunos das camadas socioeconômicas e culturalmente menos favorecidas da população brasileira, parecem não ter afetado estruturalmente a escola.

Abordando o tema da não-retenção, Glória (2003) mostra em sua pesquisa $^{3}$ que a estratégia política da eliminação da reprovação, ao favorecer a promoção dos alunos sem atingir sua principal finalidade que é a aprendizagem efetiva dos conhecimentos básicos, acaba produzindo obstáculos para o aluno continuar os estudos e também para ingressar no mercado de trabalho. As entrevistas, realizadas pela pesquisadora com pais e alunos de escola pública mineira que havia eliminado o regime seriado e instituíra três ciclos de formação básica, revelam o processo de "sobrevivência" no $3 .^{\circ}$ ciclo de alunos com idade de 12 a 15, já reprovados no regime anterior. Segundo a autora (2003, p. 70), "a vivência da experiência de reprovação constituiu um dos critérios estabelecidos para a seleção dos alunos, de modo a se perceber se houve mudanças nas percepções e nas práticas após a eliminação da reprovação escolar".

3 Dissertação de Mestrado A escola dosquepassam sem saber: a prática da não-retenção escolar na narrativa de professores, alunos e familiares. PUC/MG, 2002. 
Um aspecto básico analisado pela pesquisadora foi que a ausência de reprovação ("bomba", no dizer dos entrevistados) era percebida pelos entrevistados como "péssima" porque passavam "sem saber" aquilo que poderia lhes garantir acesso a um emprego, "ao menos de embalador", mas que para isso precisariam saber ler "para não misturar as coisas". O estudo apontou que:

(...) a não-retenção escolar conduz a uma forma de exclusão ainda mais perversa que a anterior, por permitir a permanência na escola, mas sem propiciar uma aprendizagem efetiva. E, ao final do ensino fundamental, a escola outorga um certificado esvaziado de valor social, que atesta, na verdade, mais a incompetência do que a competência, quer para o prosseguimento dos estudos, quer para facilitar o ingresso no mundo do trabalho (GLÓRIA, 2003, p. 75).

O fraco desempenho dos alunos da educação básica tem sido freqüentemente apontado nos relatónios de avaliação do SAEB (Sistema de Avaliação da Educação Básica). Ao transformar o ensino seriado em ciclos e eliminar a reprovação, tais alterações trouxeram novos desafios para a gestão da aprendizagem, suscitando mudanças nas formas de avaliar.

\section{Exclusão e Avaliação}

Apesar das inovações das políticas públicas voltadas para a democratização da educação básica, as práticas de avaliação têm continuado conservadoras, restritas à contabilização dos erros e acertos produzidos pelos alunos. Com a eliminação da reprovação, a avaliação escolar "deveria" abandonar o caráter seletivo e autoritário que tem marcado o ensino, especialmente o ensino de Matemática, motivo de grande preocupação para a comunidade educacional brasileira. A cada estatística divulgada sobre o desempenho dos alunos da educação básica, a Matemática aparece com um grande percentual de baixo desempenho, apontando o baixo índice de aproveitamento dos estudantes, o que reforça os mitos de ser uma disciplinada rejeitada pelos alunos. Ao contrário desta situação, a ciência matemática tem contribuído significativamente para o avanço científico e tecnológico dos últimos séculos.

Um dos obstáculos que tem desafiado os educadores parece ser 0 "como" avaliar a aprendizagem do aluno. Perrenoud (1993), referindo-se ao conservadorismo das práticas pedagógicas, mostrou a resistência dos professores em relação às mudanças quando afirmam: "não mexam na minha avaliação", por considerarem que a avaliação da aprendizagem poderia ser uma grande alavanca para a escola cumprir seu compromisso com a aprendiza- 
gem, já que a pior exclusão que vivemos é exclusão do conhecimento. "Mexer" na avaliação seria, para o autor, transformar as práticas escolares que, ao longo da história, têm emitido, cada vez mais, a mensagem de dizer se o aluno é bom, mais ou menos, ou mal em cada um dos componentes curriculares. Com isso, a escola tem cultuado a conhecida curva da "normalidade", distribuindo os alunos segundo a famosa curva de Gauss, onde os melhores estão no topo, os regulares, no meio e os ruins estão na base. Nessa pedagogia de resultados, a nota tem sido sempre um recado que a escola emite ao aluno em relação ao que lhe pode acontecer "se continuar assim"...O sentido dessa crítica pode ser localizado em Foucault (1991), quando aponta os papéis certificativo, classificatório e punitivo dos exames escolares, mostrando como saber e poder estão complexamente emaranhados. Fazendo a microanálise desse fenômeno, o autor aborda o exame como um mecanismo regulador da distribuição desigual do conhecimento pela instituição escolar:

o exame permite ao mestre, ao mesmo tempo em que transmite seu saber, levantar um campo de conhecimentos sobre seus alunos (...) essa prática garante a passagem dos conhecimentos do mestre ao aluno, mas retira do aluno um saber destinado e reservado ao mestre (FOUCAULT, 1991, p. 166).

O autor observa que a disciplinarização que permeia o cotidiano escolar nem sempre se torna visível para todos e que a distribuição do poder e dos corpos nos espaços são táticas utilizadas pelas economias dominantes para controle do saber e manipulação do poder. Essa interpretação que expressa o significado de uma avaliação classificatória e excludente possibilita a compreender como o ritual burocrático dos contratos pedagógicos escolares, ao definir normas institucionais, reforça a hierarquia social excluindo, pelo sistema de avaliação, barrando grande parcela da população à inserção social. Um ataque a essa "regulação perversa" seria um trabalho de ressignificação da prática docente, enquanto religação dos elos perdidos no compromisso docente com a formação do aluno.

Mostrando que ao longo da pedagogia o exame foi perdendo sua dimensão educativa, Barriga (1999, p. 64-65) afirma que não é o exame que irá resolver problemas cujas causas estão em outras instâncias sociais. Descrevendo a evolução do exame, enquanto instrumento de controle, mostra como a pedagogia foi criando, durante o século XX, outros mecanismos, substituindo este instrumento pelo teste e posteriormente por avaliação. Destaca, também, como a "euforia do teste" nos Estados Unidos, ao transitar da engenharia à pedagogia, reforçou "a paixão pelas medidas exatas", implicando numa verdadeira onda de "curvas normais", que justificava o acesso à escola, de acordo com as condições individuais. Segundo o autor, essa "violência epistemológica" esteve muito tempo articulada ao positivismo e especialmente à psicologia 
experimental, com o poder de decidir sobre o lugar social que correspondia a cada pessoa ocupar.

O exame era um espaço público para mostrar a competência que se havia adquirido Na Didactica Magna (1657) de Comenius o exame está indissoluvelmente ligado ao método que pode ajudar a aprender. Portanto, através do exame não se decide nem a promoção do estudante nem sua nota. Esta não existe até o século XIX. Comenius fecha portas falsas à atuação docente. Quando o aluno não aprende, o autor recomenda que o professor revise seu método. Ainda assim explicitamente indica que o aluno não deve ser castigado porque criaria uma aversão ao estudo. Nessas condições, 0 professor deve regressar a seu método, seu instrumento central de trabalho, e desde aí apoiar o processo de aprendizagem. Esta é na realidade sua tarefa (BARRIGA, 1999, p.60).

Quais as possibilidades de a avaliação da aprendizagem deixar de ser um mecanismo da exclusão escolar? Considerada, hoje, como processo mediador na construção do currículo, como a avaliação se relaciona com a gestão da aprendizagem dos alunos?

\section{Avaliação Formativa}

Na tentativa de recolocar o conceito, Hadji (2001) afirma que toda avaliação, seja ela prognóstica, cumulativa, formativa, é o núcleo da ação de formação, pois todas as informações ali contidas podem ser úteis ao ajuste do processo ensino/aprendizagem. Entretanto, diz o autor, nem todas as ações de formação revelam os diálogos que mantêm com os sujeitos envolvidos. Dar forma às ações dos sujeitos possibilita conhecer os significados, dados por eles, a essas ações.

Se, para o professor de Matemática, a aprendizagem de uma operação significa não apenas o domínio do algoritmo, sobretudo a compreensão do conceito envolvido, isto vai se refletir, não somente na definição das características das tarefas propostas, como também na seleção dos instrumentos de análise da produção dos alunos, portanto, exige um novo "contrato didático" (PINTO, 2003).

Nessa perspectiva de formação, avaliar a aprendizagem do aluno é uma tarefa complexa que exige não só olhar para os resultados objetivos das provas, sobretudo para os processos utilizados pelos alunos na resolução das situações-problema. Nesse sentido, uma avaliação formativa está inscrita numa pedagogia diferenciada que, ao contrário de uma pedagogia de exame, necessita contextualizar as respostas dos alunos, enquanto sujeitos históricos 
que aprendem matemática em determinadas condições. É o conhecimento situado que estará em processo de julgamento, não o aluno.

Uma avaliação formativa, antes de tudo, é parte integrante de um processo educativo onde os erros são considerados como momentos na aprendizagem e não como falhas repreensíveis ou manifestações patológicas. Nessa concepção, uma resposta "errada" é apenas um dado bruto que necessita ser analisado e interpretado pelo professor. Mais que uma resposta, ou um "vírus a ser eliminado", o erro é uma questão que o aluno coloca ao professor. Assim, o que diferencia a verificação do rendimento escolar de uma avaliação da aprendizagem é que esta se vale de uma ação inquiridora do avaliador a respeito da complexidade do processo de aprender determinado conteúdo, em determinadas circunstâncias. Não se trata de uma especulação em torno de acertos e erros ou de eliminar, da avaliação, todos os aspectos que não sejam diretamente mensuráveis, aqueles que mais se adequam ao campo qualitativo. Como lembra Steban:

como prática de investigação não se limita á distinção entre saber e não saber, que reduz a dimensão processual da construção de conhecimentos, investe na busca do ainda não saber, que trabalha com a ampliação do conhecimento, movimento permanente em que há sempre conhecimentos e desconhecimentos. $\mathrm{O}$ ainda não saber abre espaço para a multiplicidade sem colocar rótulos no sujeito que conhece e estimula a reflexão sobre os diversos percursos possíveis, valorizando a heterogeneidade e a promoção do novo (STEBAN, 2001, p. 166).

Tal como na pesquisa científica do campo educacional, a credibilidade dessa avaliação requer outros critérios, de rigor e cientificidade, não centrados na medida. Numa avaliação do rendimento escolar, em sua forma cumulativa, esses critérios são expressos por gráficos, levantamentos estatísticos e tabelas. Na concepção de avaliação formativa que estamos analisando, por se tratar de uma avaliação qualitativa, tal como na abordagem de pesquisa qualitativa, a construção da rigorosidade não é buscada nas ciências exatas. Uma de suas características é ser predominantemente descritiva e indutiva, por isso impossível de ser reduzida a escala numérica.

Da mesma forma, como sua prioridade é estabelecer um diálogo com o processo, não apenas realizar um balanço dos resultados suscitados por uma certificação, sua comunicação não se restringe à emissão de notas e boletins, porém se revela no quadro de referências que nutre as ações pedagógicas. Se a avaliação tradicional não comunica o que o mestre faz com os dados obtidos, não diz "se" e "como" reflete sobre eles e replaneja suas ações, a grande tarefa de uma avaliação que pretende garantir a aprendizagem do aluno seria recolher, organizar, analisar e interpretar o conhecimento que se 
oculta nos processos de aprender, nas representações e concepções do aluno que aprende, tornando "o familiar estranho, o comum problemático", desenvolvendo, no campo da aprendizagem, uma leitura mais "densa", um ato investigativo rigoroso, ou seja, desenvolver processos avaliativos, até então, inusitados nas práticas avaliativas classificatórias e autoritárias (GEERTZ, 1989).

Ressaltando a importância de uma prática avaliativa investigativa, Steban (1999, p.24) afirma:

A avaliação como prática de investigação tem o sentido de romper as barreiras entre os participantes do processo ensino/aprendizagem e entre os conhecimentos presentes no contexto escolar. (...) Investigando o processo ensino/ aprendizagem o professor redefine o sentido da prática avaliativa. A avaliação como um processo de reflexão sobre e para a ação contribui para que 0 professor se torne cada vez mais capaz de recolher indícios, de atingir níveis de complexidade na interpretação de seus significados, e de incorporá-los como eventos relevantes para a dinâmica ensino/aprendizagem.

A avaliação, na perspectiva da inclusão do aluno, confunde-se mesmo com o ato de aprender, enquanto momento de repensar conceitos, selecionar idéias, criar estratégias, mobilizando, portanto, o espaço mais complexo e oculto envolvido na aprendizagem que são as operações mentais dos sujeitos.

Assumir essa nova postura, em direção ao bom êxito escolar do aluno, em especial, à sua formação, requer um trabalho mais rigoroso de busca, análise e interpretação de dados, para além de um olhar normativo sobre 0 processo de ensino e de aprendizagem. Postura que se inicia no momento em que o educador reflete sobre os significados dos erros e acertos dos alunos preocupando-se em compreender os diferentes processos que os alunos utilizam ao apropriar-se dos conhecimentos, ao inquietar-se frente aos resultados obtidos e buscar sua regulação. Entretanto, a concretização de uma nova prática de avaliação requer, mais que novas posturas e novas reflexões, um bom referencial teórico-metodológico, capaz de fundamentar a busca e instrumentalizar as ações.

Praticar a avaliação, enquanto investigação, é não só reconhecer os métodos que utiliza, mas compreender onde eles estão enraizados, fator considerado de grande relevância quando se pretende tomar decisões em relação à avaliação. No final do século XIX, os cientistas sociais alegavam que os fenômenos humanos eram muito complexos e dinâmicos para serem tratados por leis gerais como na física e na biologia. Para compreender um fenômeno humano, no caso, o processo de aprendizagem dos alunos, seria preciso compreender os vários fatores que o influenciavam, cada um à sua maneira. Nas ciências naturais, os objetos de estudo descartam tais influências. As- 
sim, é possível estudar uma rocha ignorando sua consciência histórica, sua ideologia, sua cultura, do sentido que dá a suas ações e a sua vida (DÉPELTEAU, 1998, p. 79).

Enquanto fenômeno humano, a avaliação da aprendizagem está comprometida com o bom êxito do aluno, com seu conhecimento informal, seu desenvolvimento cognitivo e muitos outros aspectos além dos objetivos da escola. Para gerir essa complexa rede de conhecimentos, na qual está imersa a avaliação, o avaliador precisa assumir que essa nunca é completa. Enquanto investigação, como toda pesquisa, ela é um recorte de uma realidade complexa. Um dos grandes fundamentos epistemológicos da ciência moderna é que nas ciências humanas o sujeito e o objeto são humanos, o que torna mais difícil para os pesquisadores observar seu objeto de estudo com neutralidade. É muito mais difícil estabelecer um distanciamento entre seres humanos. A mesma prova pode receber avaliações diferentes, quando avaliada por diferentes professores. Avaliar um fenômeno humano requer, mais que explicação, a compreensão de suas finalidades. Compreender a avaliação, enquanto processo investigativo, cujo foco está centrado nos significados atribuídos pelos sujeitos às suas ações, requer colocá-la dentro de um contexto. Praticar, pois, uma avaliação formativa é assumir um modo de investigação apropriado para compreender (e também explicar) o fenômeno da aprendizagem, sem excluir a carga de subjetividade dos saltos cognitivos que emergem no percurso de quem aprende. Modo este essencialmente hermenêutico que, ao preocupar-se com a interpretação dos significados contidos num texto, leva em conta cada mensagem e suas inter-relações. Opondo-se à visão empiricista de ciência, busca a interpretação, em lugar da mensuração, a descoberta, em lugar da constatação, valoriza a indução e assume que fatos e valores estão intimamente relacionados, tornando-se inaceitável uma postura neutra do pesquisador.

Avaliar, tendo em vista a aprendizagem efetiva dos alunos, é sobretudo descrever os processos nela envolvidos, bem como as relações que os sujeitos estabelecem com o saber. Trata-se mais de uma "descrição densa", uma etnografia (GEERTZ, 1989) da cultura, no caso, como lembra Pozo (2002, p. 30), uma cultura da aprendizagem que está imersa na crise desencadeada pelas novas necessidades sociais geradas "pela explosão informativa e do conhecimento", implicando em "demandas de aprendizagem que não podem ser comparadas com as de outras épocas passadas, tanto em qualidade como em quantidade". Segundo este autor, a imagem da aprendizagem tradicional, baseada na apropriação e reprodução "memorística" dos conhecimentos, sofre uma crescente deterioração progressiva, abalada pelas mudanças sociais, tecnológicas e culturais. 
As características dessa nova cultura da aprendizagem fazem com que as formas tradicionais da aprendizagem repetitiva sejam ainda mais limitadas que nunca. Em nossa cultura, a aprendizagem deveria estar direcionada não tanto para reproduzir ou repetir saberes que sabemos parcialmente, sem mesmo pô-los em dúvida, como para interpretar sua parcialidade, para compreender e dar sentido a esse conhecimento, duvidando dele. A cultura da aprendizagem direcionada para reproduzir saberes previamente estabelecidos deve dar passagem a uma cultura da compreensão, da análise crítica, da reflexão sobre o que fazemos e acreditamos e não só do consumo, mediado e acelerado pela tecnologia, de crenças e modos de fazer fabricados fora de nós (POZO, 2002, p. 40).

Se falar em avaliação formativa é, como afirmou Perrenoud (1999, p. 108), referir-se a uma pedagogia diferenciada, portanto, "mais aberta, ativa, individualizada, abrindo mais espaço à descoberta, à pesquisa, aos projetos, honrando mais os objetivos de alto nível", seus métodos, certamente, não serão os mesmos utilizados numa avaliação tradicional, que segundo o autor, tem servido de obstáculo à transformação das práticas pedagógicas. Para dar informações e alimentar a ação pedagógica, utiliza métodos qualitativos, gerados nas lutas contra as discriminações sociais e culturais e na busca de igualdade de direitos.

Ao conhecer, analisar e interpretar os pontos de vista dos alunos, dá informações e alimenta a ação pedagógica, com novos conhecimentos em relação às lógicas e estratégias utilizadas pelos alunos em seu processo de apropriação do saber escolar. Ao contrário da avaliação tradicional, voltada para a certificação e para o balanço do final do ano ou de um ciclo de aprendizagem, a avaliação formativa está centrada na gestão da aprendizagem dos alunos estabelecendo, com eles, um diálogo amplo e contínuo, a respeito do objeto de saber. Gerada no campo das teorias cognitivistas de aprendizagem, nas quais o ensino é um processo aberto e diferenciado, individualizado e adaptado a alunos de ritmos diferentes de aprendizagem, a avaliação formativa busca avaliar o aluno ao longo de todo o processo de aprendizagem, não tendo por finalidade determinar o rendimento num dado momento. Sua natureza é formadora e sua função é orientar, informar, regular, melhorar, conscientizar, individualizar. Ao descrever qualitativamente o desenvolvimento do aluno e tomar consciência de suas dificuldades, sua finalidade é reconhecer "onde" e "em quê" o aluno sente dificuldade, procurando não só informá-lo, mas propiciar-lhe formá-lo no sentido (PERRENOUD, 1999). Enquanto um feedback para o aluno e para o professor, a "boa" avaliação formativa requer tomada de decisões e exige registros, análise e interpretação dos dados. Uma interpretação construtivista da aprendizagem requer, também, uma concepção construtivista de interpretação pedagógica. Segundo Hadji: 
A avaliação só é formativa se for informativa. E só é informativa se responder a perguntas! 0 que se deve saber sobre o 'objeto' avaliado?Se ele é capaz de... (fazer o quê ? Será preciso determinar isso?). Se compreendeu (o quê exatamente?). Se sabe, se sabe fazer, se sabe ser... (o quê?) Com efeito não há avaliação sem pergunta feita à realidade. (...) É essa interrogação que designa (e cria) o objeto da avaliação. 0 avaliador deverá, então, com todo o rigor, expressar essa interrogação (2001, p.79).

Como sua finalidade não são as notas, as "provas formativas" não podem ser interpretadas em termos de desvio de média ou classificação, apenas em termos de situação do aluno no seu próprio percurso de aprendizagem.

\section{Processos Avaliativos Includentes}

Uma avaliação, antes de tudo, é parte integrante de um processo educativo onde os erros são considerados como momentos na aprendizagem e não como falhas repreensíveis ou manifestações patológicas. No entanto, numa "pedagogia da resposta", centrada nos resultados, o espaço da avaliação é a memória, lugar de acumular, quantificar, de se preocupar em dar explicações precisas (MEIRIEU, 1998). Essa pedagogia, como diz o autor:

ensina lições que, dentro de um certo tempo, sem dúvida, permitirão resolver problemas...mas problemas que apenas serão encontrados mais tarde, no final da aula, na avaliação, no exame, na 'vida'. (...) é, portanto, uma pedagogia do 'aleatório': assegura, de forma eficaz, uma função de seleção social, mas não garante a todos a apropriação do que pretende 'explicar' (MEIRIEU, 1998, p. 171).

Fundamentada nessa pedagogia, a avaliação, ao pretender homogeneizar, classifica, hierarquiza e sobretudo exclui, como diz Steban (2001, p. 181), "atua essencialmente na ótica da negação: negação do outro, do diferente, de suas práticas, de seus saberes, de suas formas de vida, de seu contexto cultural, de sua realidade social; negação do diálogo; negação das múltiplas possibilidades". Uma ponta visível desse iceberg que separa os que sabem dos que não sabem é a nota.

Segundo Barriga:

A nota escolar é um ato que se materializa no século XIX. De fato perverteu as relações pedagógicas ao centrar o resultado de um curso, e portanto sua valoração, apenas em função do exame. Por isso, pode-se afirmar que a 
atribuição de notas não responde a um problema educativo nem está forçosamente ligada à aprendizagem. Sua tarefa se aproxima mais do poder e do controle (...) A nota só é uma convenção através da qual a escola certifica um conhecimento (1999, p. 78-81).

Numa pedagogia diferenciada, "pedagogia do problema", o espaço da avaliação é mais complexo e não está tão facilmente visível: são as operações mentais dos alunos, as deduções e induções que realizam e a dialetização que as relaciona que interessam ao professor. Tais operações não funcionam no vazio; por trás delas, como afirma Meirieu (1998), existem conteúdos para dar-lhes significância de aprendizagem. O grande desafio, segundo o autor, é o professor "traduzir os conteúdos de aprendizagem em procedimentos de aprendizagem, ou seja, em uma seqüência de operações mentais que ele procure compreender e instituir na sala de aula". A complexidade dessa pedagogia é colocar para o professor um grande desafio: para se criar um dispositivo didático adequado ao aluno é preciso conhecer a natureza da atividade intelectual a ser desenvolvida e buscar as condições que garantam seu êxito.

No ensino de Matemática, esse desafio se expressa na escolha das situações-problema que possam realmente ser um "problema" para o aluno e evitar que se transforme em exercício de repetição, o que levaria 0 professor a permanecer na restrita e trivial avaliação de resultados, classificatória e hierárquica.

Allal (1995, p. 157) faz distinções entre uma avaliação formativa orientada por uma abordagem behaviorista e uma avaliação formativa orientada por uma perspectiva cognitivista. No behaviorismo tipo skinneriano, o ensino deve ser programado para assegurar uma "aprendizagem sem erro". Assim, não necessita de procedimentos para adaptar o ensino em função das dificuldades encontradas pelo aluno.

Na perspectiva de Bloom, Gagné, Glaser e outros néobehavioristas, os instrumentos são buscados no quadro referencial da pedagogia do domínio ou ensino modular. A avaliação está alicerçada nos objetivos, definidos em termos de comportamentos observáveis. As informações, de natureza "objetiva" estão ancoradas nos desempenhos apresentados pelos alunos em relação aos objetivos estabelecidos. A coleta de dados fornece dados quantitativos buscados em testes e exercícios escritos, cujas questões remetem a uma resposta fechada, tipo lacunas, múltipla escolha. São também utilizadas grelhas de observações para o registro bem preciso do comportamento do aluno. A interpretação dos dados é feita a partir de referência criterial: comparando os desempenhos do aluno com os objetivos preestabelecidos. A apreciação resultante é expressa em conceitos: suficiente, 
insuficiente, adquirido, em vias de aquisição, não adquirido. Nessa abordagem, segundo Allal (1995), as soluções propostas são atividades de recuperação, repetição da lição inicial, mais exercícios do mesmo tipo, em alguns casos, diversificação da modalidade e natureza das tarefas, funcionando como remediação preventiva ( paliativos) para a eliminar o "contágio" dos erros.

Na tendência cognitivista, cujos referenciais são oriundos da epistemologia genética de Piaget e dos trabalhos de Bruner, sobre a aprendizagem por descoberta, a coleta de informações sobre os resultados não é prioridade. A ênfase é dada aos processos de aprendizagem, à compreensão do funcionamento cognitivo do aluno face à tarefa proposta. Os dados que interessam são as representações que os alunos formulam sobre as tarefas e os procedimentos ou estratégias que utilizam para chegar a algum resultado. Nesse sentido, a reflexão e a análise dos erros produzidos pelos alunos pelo fato de revelarem a natureza das construções e representações utilizadas pelo aluno no seu processo de aprender, contribuem para a mudança das práticas de avaliação. $\mathrm{O}$ erro produzido pelo aluno pode ser considerado como um observável de grande significância para a avaliação formativa quando concebido, não como falha, ausência, um "vírus que deve ser imediatamente eliminado", mas como elemento natural do processo de conhecer. No entanto, para que possa ser realmente um "observável para o aluno" deve ser antes um " observável para o professor", compreendido, não como simples resposta errada, mas como uma questão que o aluno coloca ao professor no decorrer de seu processo de construção de conhecimento, ou seja, utilizado pelo professor não para sancionar e culpabilizar o aluno, mas como estratégia didática de grande potencialidade para a reorientação do ensino (PINTO, 2000). No estudo realizado com uma turma das séries iniciais do ensino fundamental, a autora aponta a análise de erros como instrumento relevante para a avaliação formativa, pela qualidade de informações que fornece ao professor em relação às origens dos erros. $\mathrm{O}$ estudo mostrou que um ensino de Matemática, excessivamente marcado pela algoritmização, limita a visibilidade de erros conceituais. Mostrou ainda que muitos erros são originários da própria natureza das tarefas propostas aos alunos.

Cardinet (1993), ao estudar os erros de adição e subtração, apontou que as principais dificuldades encontradas pelos alunos, para o domínio da subtração, localizam-se não no campo da matemática, mas no campo da lingüística.

Hadji (2001, p. 99) afirma não ser surpreendente o fato de que "a língua seja fonte de dificuldade para alunos jovens", pois "as operações propriamente matemáticas mobilizam outros savoir-faire, instrumentais, den- 
tre os quais o domínio das relações temporais, a compreensão da escrita etc.". A análise de erros, enquanto meio, possibilita que os erros sejam explorados e compreendidos a partir de suas origens, fornecendo valiosos subsídios para o professor planejar a partir de uma pedagogia diferenciada ações pertinentes à evolução do processo.

\section{Considerações Finais}

Se a avaliação da aprendizagem escolar pode ser um mecanismo de reforço da exclusão social, assumir uma avaliação como prática investigativa, mais que um compromisso, é uma atitude profissional voltada para ajudar o aluno a se apropriar dos conhecimentos e habilidades elementares para a entrada no mercado de trabalho. Em sentido mais amplo, é uma ação fundamental para a concretização de uma prática mais profissionalizada e comprometida com a emancipação do aluno, enquanto sujeito do conhecimento. Compreendê-la, como um espaço de construção de conhecimentos acerca do processo de aprendizagem, é aceitar sua íntima relação com o ensino e portanto percebê-la imersa num contexto histórico e cultural que permite movimentar-se e ultrapassar fronteiras. Colocá-la, portanto, a favor de uma política de democratização da educação básica é, especialmente, avaliar a experiência matemática dos alunos, no contexto de uma pesquisa qualitativa a partir do princípio educativo que os alunos são diferentes e nunca desenvolvem um mesmo percurso de aprendizagem. Outro princípio é que o êxito escolar não depende apenas de uma capacidade individual para a matemática, mas está relacionado aos inúmeros fatores culturais que estão implícitos na experiência matemática de cada indivíduo. Os métodos e instrumentos oriundos da pesquisa qualitativa, pela forma de interpretar a aprendizagem, penetrando nos espaços ocultos do "triângulo didático", ou seja, no núcleo da formação dos conceitos matemáticos, ao indagar e procurar compreender como ocorre o processo cognitivo dos sujeitos que aprendem matemática, essa abordagem metodológica permite descrições muito mais ricas e inteligíveis que os métodos quantitativos.

Em última instância considera-se que um trabalho de avaliação voltado à inclusão do aluno é um problema que deve levar em conta a necessidade de preparar os educadores para essas novas tarefas. 


\section{Referências}

ALLAL, L Stratégies d'évaluation formative: conceptions psycho-pédagogiques et modalités d'application. In: ALAL, L; CARDINET, J; PERRENOUD, PH. L'evaluation formative dans un enseignement différencié. 7. ed. Suisse: Peter Lang, 1995. p. 153-183.

BARRIGA, A.D. Uma polêmica em relação ao exame. In: STEBAN, M.T. ( Org.). Avaliação: uma prática em busca de novos sentidos. Rio de Janeiro,RJ: DP\&A, 1999. p. 51-82.

CARDINET, J. _Avaliar é Medir ?. Portugal: Asa, 1993.

DÉPELTEAU, F. La démarche d'une recherche en sciences humaines: de la question de départ á la communication des résultats. Canada: Les Presses de l'Université Laval, 1998.

DUBET, F. A escola e a exclusão. Cadernos de Pesquisa, São Paulo, n. 119, p. $29-45$, jul. 2003

FOUCAULT, M. Vigiar e Punir: nascimento da prisão. 9 ed. Petrópolis: Vozes, 1991.

GEERTZ, C. A interpretação das culturas. Rio de Janeiro,RJ: Guanabara Koogan, 1989.

GLÓRIA, D.M.A. A "escola dos que passam sem saber": a prática da nãoretenção escolar na narrativa de alunos e familiares. Revista Brasileira de Educação. Campinas, n.22, p. 61- 76, jan./abr. 2003,

HADJI, C. Avaliação demistificada. Porto Alegre: ArtMed, 2001.

MEIRIEU, Ph. Aprender...Sim, mas como? 7.ed. Porto Alegre: Artes Médicas, 1998.

PERRENOUD, Ph. Não mexam na minha avaliação! Para uma abordagem sistêmica da

Mudança pedagógica. In: ESTRELA, A; NÓVOA, A . (Orgs.). Avaliações em educação: novas perspectivas. Porto: Porto, 1993. p. 171-191.

PERRENOUD, Ph. Avaliação: da excelência à regulação das aprendizagens: entre duas lógicas. Porto Alegre: Artes Médicas Sul, 1999.

PINTO, N. B. 0 erro como estratégia didática: estudo do erro no ensino da matemática elementar. Campinas: Papirus, 2000. 
PINTO, N. B. Contrato didático ou contrato pedagógico? Revista Diálogo Educacional,Curitiba, v.4, n.10, p. 93- 106, set./dez. 2003.

POZO, J.Y. Aprendizes e mestres: a nova cultura da aprendizagem. Porto Alegre: Artmed, 2002.

STEBAN, M.T. A avaliação no cotidiano escolar. In: STEBAN, M.T. (Org.). Avaliação: uma prática em busca de novos sentidos. Rio de Janeiro,RJ: DP\&A, 1999. p. 7-28.

STEBAN, M.T. O que sabe quem erra? Reflexões sobre a avaliação e fracasso escolar. Rio de Janeiro,RJ: DP\&A, 2001.

Recebido: 12 de abril de 2006 Aceito: 28 de julho de 2006 